
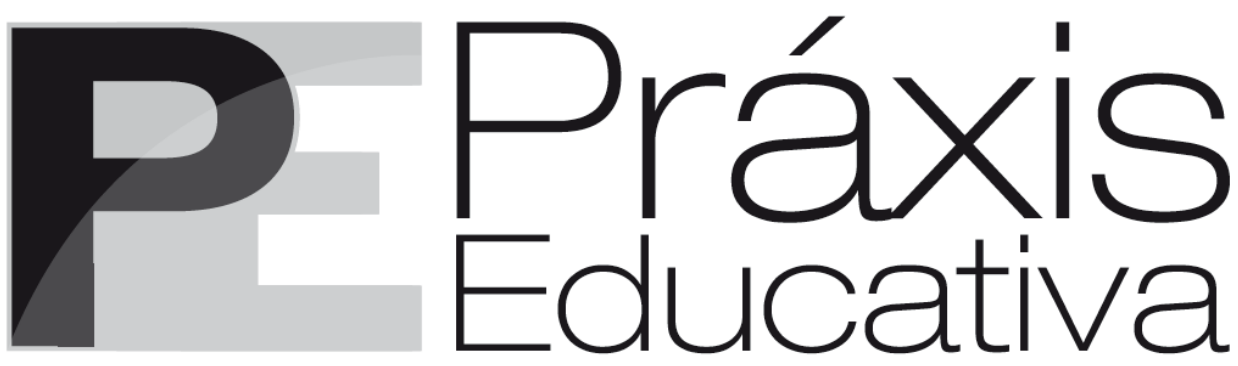

ISSN 1809-4309 (Versão online)

DOI: 10.5212/PraxEduc.v.12i3.017

\title{
Representações sociais de ciência e gênero no ensino de Ciências
}

\section{Social representations of science and gender in Science teaching}

\section{Representaciones sociales de ciencia y género en la enseñanza de Ciencias}

\author{
Bettina Heerdt ${ }^{*}$ \\ Irinéa de Lourdes Batista*
}

Resumo: Este artigo analisa as representações sociais (RS) de docentes a respeito da Natureza da Ciência $(\mathrm{NdC})$, das questões de gênero na sociedade, na Ciência e no contexto de ensino. A abordagem teórica é a da RS dimensional de Moscovici, associada às discussões da $\mathrm{NdC}$, teorias feministas da Ciência e Ensino de Ciências. Participaram da investigação 22 docentes. Os dados foram coletados por meio do registro fílmico. A análise lexical foi realizada com o auxílio do software Alceste. Formaram-se quatro classes: NdC, Gênero e a mulher na Ciência, Gênero e contexto de ensino, e Gênero e sociedade. Nas áreas de formação das/dos docentes, não foi possível encontrar diferenças significativas nas RS. Por meio dos dados empíricos, percebe-se a argumentação distinta de homens e de mulheres. A RS dos homens, naturalizada, discriminatória e de negação das questões de gênero na sociedade e na Ciência, mostra-se mais contundente do que das mulheres. Faz-se necessária, na formação inicial e continuada, a problematização das questões de gênero na Ciência.

Palavras-chave: Representações sociais. Gênero e Ciência. Formação docente.

\begin{abstract}
This paper analyzes the Social Representations (SR) of teachers regarding the Nature of Science $(\mathrm{NoS})$, gender issues in society, Science and in the teaching context. The theoretical approach is Moscovici's SR associated to NoS discussions, Science feminist theories and Teaching of Science. A number of twenty-two teachers were part of this research. Data were collected through the filmic record. The lexical analysis was performed using the Alceste software. Four classes were formed: NoS, Gender and women in Science, Gender and teaching context, and Gender and society. In the areas of the teachers' education, it was not possible to find significant differences in SR. Through empirical data, the distinct argumentation of men and women is noticed. The SR of men, naturalized, discriminatory and of gender issue denial in society and Science, is more forceful than of women. It is necessary, in the initial and continued education, the problematization of gender issues in Science.
\end{abstract}

Keywords: Social representations. Gender and Science. Teacher education.

Resumen: En este artículo se analizan las representaciones sociales (RS) de docentes acerca de la Naturaleza de la Ciencia $(\mathrm{NdC})$, de las cuestiones de género en la sociedad, en la Ciencia y en el contexto de la Enseñanza. El abordaje teórico es el de la RS dimensional de Moscovici asociado a las discusiones de la $\mathrm{NdC}$, teorías feministas de la Ciencia y Enseñanza de la Ciencia. Participaron de la investigación 22

\footnotetext{
* Professora da Universidade Estadual de Ponta Grossa - UEPG. E-mail: < bettina_heerdt@yahoo.com.br>.

** Professora da Universidade Estadual de Londrina - UEL. E-mail: <irinea2009@gmail.com>.
} 
docentes. Los datos fueron recolectados por medio del registro fílmico. El análisis lexical fue realizado con el auxilio del software Alceste. Se formaron cuatro clases: Ndc, Género y la Mujer en la Ciencia, Género y contexto de Enseñanza y, Género y sociedad. En las áreas de formación de los docentes no fue posible encontrar diferencias significativas en las RS. Por medio de los datos empíricos, se percibe la argumentación distinta de mujeres y hombres. La RS de los hombres naturalizada, discriminatoria y de negación de las cuestiones de género en la sociedad y en la Ciencia, se muestra más contundente que la muestra de las mujeres. Se hace necesaria, en la formación inicial y continuada, la problematización de las cuestiones de género en la Ciencia.

Palabras clave: Representaciones sociales. Género y ciencia. Formación docente.

\section{Introdução}

Os estudos de gênero problematizam os contextos em que se inserem homens e mulheres e as interseções com as categorias socioculturais como etnias, raça, classe, sexualidade, entre outras (SCOTT, 1995). Esses contextos, em que as mulheres são diferentes, sofrem pressões, discriminações e abusos socioculturais distintos (LOURO, 2008). Isso indica o gênero como uma construção social e cultural permeada pelas relações de poder (SCOTT, 1995; LOURO, 2003).

As representações de gênero são construídas culturalmente e definem os lugares de homens e de mulheres na sociedade (LOURO, 2008). Suas representações estão presentes na Ciência e no Ensino de Ciências de maneira complexa, naturalizada, reafirmando preconceitos e discriminações (SCHIEBINGER, 2001; HUSSÉNIUS, 2014; HEERDT; BATISTA, 2016a). As pesquisas de gênero e Ciência sobre a produção do conhecimento científico, na perspectiva crítica feminista, revelam a desigualdade de mulheres na Ciência e nos cargos de decisão (OSADA; COSTA, 2006; KELLER, 2006; HARDING, 1996, 2010; HARAWAY, 1992, 1995; LONGINO, 1987; LONGINO; DOELL, 1983). Nos estudos de gênero e Educação Científica, pesquisadores relatam o desinteresse das mulheres pela Ciência, o tratamento diferenciado dado por docentes a meninos e meninas, e a formação docente (SINNES; LOKEN, 2014; HUSSÉNIUS, 2014; HEERDT, 2014; BOURDIEU, 2014).

Do ponto de vista educacional, preocupam as dicotomias e as polarizações que atravessam a construção do conhecimento científico e as representações de gênero naturalizadas em nossa sociedade e no meio escolar. Sendo o conhecimento científico construído em um determinado contexto social e cultural e os homens e as mulheres sujeitos históricos e socialmente situados, defende-se a ideia de um saber situado, sem atribuir privilégio, mas, sim, singularidade (HEERDT, 2014).

O conceito central da epistemologia feminista é o de um conhecimento situado, proposto por Haraway (1995). Anderson (2011) apresenta diversos fatores que permitem que cada conhecedor compreenda um mesmo objeto de maneiras distintas. Apesar de a epistemologia feminista situada salientar a contextualização e a relatividade de muitos conhecimentos, eles não estão de acordo com a ideia de relativismo epistemológico.

Silva, Santos e Heerdt (2017), ao analisarem 33 artigos de 13 revistas nacionais e internacionais online relacionadas ao Ensino de Ciências, dos estratos A1, A2 e B1, encontraram no âmbito internacional 25 artigos de pesquisas de gênero e Educação Científica e oito nacionais. A revista Cultural Studies of Science Education lançou, em 2014, uma edição especial - Science education for all, some or just a few? Feminist and gender perspectives on science education: a special issue (HUSSÉNIUS, 2014) -, que apresenta pesquisas de gênero em educação científica com diferentes bases teóricas. Há também um número especial na Sciencie \& Education, com o título Introduction: Women, Science

Práxis Educativa, Ponta Grossa, v. 12, n. 3, p. 995-1012, set./dez. 2017 Disponível em: <http://www.revistas2.uepg.br/index.php/praxiseducativa> 
Education and Feminist Theory, organizado pela pesquisadora Cassandra L. Pinnick, em 2008, que conta com oito artigos que discutem a mulher na Ciência, as questões de gênero na Educação Científica e as teorias feministas. O consenso que existe é o de que esses estudos são interdisciplinares, emergentes e atuais. No entanto, entre esses estudos, são poucas as investigações empíricas de representações sociais, gênero e Educação Científica, o que evidência a necessidade de ampliar as pesquisas nesse campo.

A Teoria das Representações Sociais (TRS) defende que os sujeitos não apenas reproduzem, mas produzem e determinam comportamentos, significados e relações (MOSCOVICI, 2012), e possibilita a análise da diversidade de modos de conhecer e de construir a realidade. As representações sociais (RS) indicam "[...] uma forma de conhecimento, socialmente elaborada e partilhada, com um objetivo prático, e que contribui para a construção de uma realidade comum a um conjunto social" (JODELET, 2001, p. 22).

Esta pesquisa problematiza o gênero na sociedade, na Ciência e no Ensino de Ciências no contexto de formação docente na Educação Científica e tem por objetivo analisar as representações sociais de docentes da $\mathrm{NdC}$, das questões de gênero na sociedade, na Ciência e no Ensino de Ciências. Essa investigação possui um caráter transdisciplinar ao utilizar um referencial teórico das representações sociais, dos estudos de gênero e das discussões da Natureza da Ciência.

\title{
Revisão teórica
}

Arruda (2002), ao apresentar um panorama da TRS, estabelece associações com as teorias feministas de gênero. Essas teorias emergentes fazem parte de um movimento mais amplo de relação com o real e de construção do conhecimento científico. Para Arruda (2000):

\begin{abstract}
A teoria feminista vai visibilizar facetas desconhecidas até então ao descortinar a situação das mulheres, tanto com relação a problemas já identificados quanto a outros, que estavam por abordar. A teoria das representações sociais vai visibilizar facetas omitidas do conhecimento humano, valorizando o saber do senso comum, o universo consensual das conversações cotidianas e a criatividade das pessoas comuns ao traduzir a realidade. (ARRUDA, 2000, p. 119).
\end{abstract}

Ambas, teorias feministas e das RS, desalojam o conceito de verdade proposto pela Ciência tradicional, que é fortemente enraizado à ideia de que o distanciamento do olhar do/da pesquisador/a, a neutralidade, é que dá caráter científico à pesquisa, sendo esse distanciamento do objeto de pesquisa uma medida de verdade da Ciência. Esse olhar seria imparcial, impessoal e sem gênero (HARDING, 2010). Compreende-se que o conhecimento científico apresenta diferentes formas de legitimação do conhecimento do senso comum. Há, porém, um conjunto de valores que interferem na construção desse conhecimento, pois a Ciência é um empreendimento humano, desenvolvido por cientistas, mulheres e homens, que participam de uma sociedade que possui uma cultura androcêntrica.

Os ideais de neutralidade e de imparcialidade na construção do conhecimento científico são desafiados pela crítica feminista, pois vive-se em um mundo permeado pelas relações de gênero, que são desiguais. O olhar científico, portanto, não está imune a essas relações, uma vez que "[...] a segregação social e política a que as mulheres foram historicamente conduzidas tivera como consequência a sua ampla invisibilidade como sujeito, inclusive como sujeito da Ciência" (LOURO, 2003, p. 20), que ainda hoje parece reforçada pela naturalização dos papéis de gênero. Todavia, a compreensão das relações de gênero implícitas e explícitas na construção do 
conhecimento científico e na Ciência, trazidas pela consciência feminista, possibilita a desconstrução das informações ensinadas como evidentes e naturais.

A aprendizagem crítica de conteúdos e da cultura científica é necessária para que as/os docentes que medeiam, facilitam ou propiciam esse ensino tenham a clareza dos sistemas de valores que sustentam a Ciência e sua ação educativa (SALVI; BATISTA, 2008). No entanto, pesquisas mostram falta de entendimento das/dos docentes a respeito da $\mathrm{NdC}$ (AKERSON et al., 2012), o que as/os impede de perceberem também as intrínsecas relações entre a construção do conhecimento científico e as questões de gênero.

$\mathrm{Na}$ escola, RS neutras de Ciência e naturalizadas e discriminatórias de gênero são construídas, o que pode produzir e determinar comportamentos e relações. Bourdieu (2014) descreve que o comportamento da/o docente gera discriminações no momento em que meninas e meninos são estimulados desigualmente, em que meninos possuem um tratamento privilegiado, maior tempo de dedicação, são mais arguidos, raramente são interrompidos e participam mais das discussões.

O estudo das RS na educação e, de uma maneira mais ampla, na sociedade do conhecimento, pode ser considerado ingrediente indispensável para a melhor compreensão dessa sociedade. As RS são elementos simbólicos que os indivíduos expressam, utilizando palavras e gestos. Dessa forma, eles “[...] explicitam o que pensam, como percebem esta ou aquela situação, que opinião formulam acerca de determinado fato ou objeto, que expectativas desenvolvem a respeito disto ou daquilo... e assim por diante" (FRANCO, 2004, p. 170). Ao explicitar o que um indivíduo pensa, "[...] não apenas podemos inferir suas concepções de mundo, como também podemos deduzir sua "orientação para a ação" (FRANCO, 2004, p. 171), de condutas e das práticas sociais (ALVES-MAZZOTTI, 2008).

A TRS pode ser utilizada em vários campos do conhecimento e a Educação Científica pode ser um desses focos de análise, em função dessa teoria buscar compreender a origem e o funcionamento dos sistemas de referência utilizados para classificar pessoas e grupos e interpretar os conhecimentos da realidade cotidiana (ALVES-MAZZOTI, 2008). A RS destaca as construções cognitivas de um objeto social da vivência, subjetiva, mas, simultaneamente, compartilhada, pertencente, também, às esferas do intersubjetivo e do transubjetivo (JODELET, 2007). Assim, as RS revelam uma relação do sujeito com o objeto segundo dois aspectos fundamentais: o perceptivo, que implica a presença do objeto; e o conceitual, que implica a sua ausência. Representar uma coisa ou um estado não quer dizer reproduzir, mas, sim, reconstrução, modificação ou transformação à nossa maneira, dando existência, familiarizando-nos com o que não existia e era estranho para nós (MOSCOVICI, 2012).

A teoria das RS apresenta três abordagens distintas e complementares: a abordagem dimensional, a abordagem dinâmica e a abordagem estrutural. Neste artigo, para subsidiar a análise e a discussão dos dados, será utilizada a abordagem dimensional por sua natureza social. A abordagem dimensional das RS desenvolvida por Moscovici (2012) indica que as RS se organizam de acordo com as proposições, as reações ou as avaliações de cada classe, cultura ou grupo, por meio de três dimensões: a informação, o campo de representação ou imagem, e a atitude.

A informação está relacionada à organização do conhecimento de um grupo a respeito de um objeto social (neste estudo em relação à $\mathrm{NdC}$ e gênero na Ciência e sociedade). A quantidade e a qualidade de informações são diferentes entre distintos grupos sociais (MOSCOVICI, 2012). O campo de representação ou imagem remete à ideia de modelo social (modelo de Ciência e gênero) que manifesta tanto os conhecimentos interiores quanto os do 
exterior dos sujeitos, servindo para filtrar as mensagens e direcionar a interpretação dos conhecimentos e experiências (MOSCOVICI, 2012). A atitude diz respeito à orientação, à tomada de posição global favorável, desfavorável ou intermediária ao objeto de representação, "[...] revelada por um comportamento global ou por uma série de reações cuja significação é comum" (MOSCOVICI, 2012, p. 445). Essas três dimensões - conhecimento, imagens e atitudes - da representação social da NdC e de gênero podem fornecer uma visão global de seu conteúdo e sentido para o grupo de indivíduos pesquisados.

\section{Metodologia e análise das informações}

Nesta pesquisa, optou-se por uma metodologia diversificada, que possa contribuir para a compreensão da complexidade do processo investigado, uma vez que os objetivos da investigação são fenômenos sociais. As/os participantes são docentes da Rede Estadual de Ensino do estado do Paraná. Participaram da investigação 22 docentes identificadas/dos pelas seguintes características: informantes (1 ao 22), mulheres e homens $(\mathrm{M} \mathrm{e} \mathrm{H})$, área de formação (Biologia (B), Filosofia (F), Geografia (G), Letras (L), Matemática (M), não identificado (I) no momento da fala). O perfil das/dos docentes encontra-se no Quadro 1 que segue.

Quadro 1 - Perfil das/os docentes

\begin{tabular}{|c|c|c|c|c|c|}
\hline \multirow{2}{*}{ Formação } & \multicolumn{2}{|c|}{ Sexo } & \multirow{2}{*}{$\begin{array}{l}\text { Tempo } \\
\text { médio de } \\
\text { serviço }\end{array}$} & \multirow{2}{*}{$\begin{array}{c}\text { Pós- } \\
\text { Graduação } \\
\text { (Latu Sensu) }\end{array}$} & \multirow{2}{*}{$\begin{array}{c}\text { Pós- } \\
\text { Graduação } \\
\text { (Stricto Sensu }\end{array}$} \\
\hline & $\mathrm{M}$ & $\mathrm{H}$ & & & \\
\hline Ciências Biológicas & 10 & 0 & 17 anos & 10 & 1 \\
\hline Filosofia & 1 & 1 & 7 anos & 2 & \\
\hline Geografia & 0 & 2 & 13 anos & 2 & \\
\hline Letras & 3 & 0 & 19 anos & 3 & \\
\hline Matemática & 1 & 3 & 14 anos & 4 & \\
\hline Tecnólogo em eletromecânica & 0 & 1 & 8 anos & 1 & \\
\hline Total & 15 & 7 & & & \\
\hline TOTAL & & & & 22 & 1 \\
\hline
\end{tabular}

Fonte: Elaborado pelas autoras com base nos dados da pesquisa.

Os dados foram coletados durante o processo de intervenção pedagógica. A unidade didática (UD) construída foi baseada na proposta de Zabala (1998) para sequências didáticas, fundamentada em uma concepção construtivista. O objetivo desta UD é desconstruir visões equivocadas de aspectos da $\mathrm{NdC}$ e desnaturalizar o papel secundário da mulher na construção do conhecimento científico e na Ciência. O curso de extensão teve duração de 20 horas, e a descrição detalhada da UD pode ser encontrada em Heerdt (2014) e Heerdt e Batista (2016b).

A UD foi elaborada com vistas a uma abordagem explícito-reflexiva. Pesquisadores como Fouad Abd-el-Khalick e Norm Lederman (2000) defendem a utilização de abordagens explícitas na melhoria das visões de docentes em formação inicial ou em serviço da NdC. Para esses autores, essa abordagem é relativamente mais bem-sucedida do que abordagens implícitas. Nesse sentido, recomendam proposições de caráter explícito e reflexivo na tentativa de promover mudanças nas concepções epistemológicas. $\mathrm{Na}$ abordagem explícita, o ensino enfoca diretamente 
conteúdos epistemológicos, ou emprega elementos de História e Filosofia das Ciências no tratamento de conteúdos específicos (ABD-EL-KHALICK; LEDERMAN, 2000).

O corpus de análise é formado pelos questionários diagnóstico inicial e posterior com onze questões, planejamentos de aula das/dos docentes e o vídeo gravado durante a intervenção pedagógica. Neste artigo, serão apresentados os dados coletados por meio do registro fílmico de 11 horas e 21 minutos, que, após, foram transcritos e processados pelo software Alceste (Analyse Lexicale par Contexte d'un Ensemble de Segments de Texte).

No artigo de Heerdt e Batista (2016a), esses mesmos dados foram analisados por meio da análise do conteúdo temática categorial proposta por Bardin (2004). No entanto, ficaram questões que não foram respondidas por meio dessa análise, tais como as diferenças de representações sociais associadas à área de formação e ao sexo. Além disso, essa análise pode corroborar e/ou realizar novas inferências. Todo material coletado foi obtido por meio do consentimento livre, mediante o compromisso ético em manter preservada a identidade das/dos docentes.

Para o processo de análise dos dados, foi utilizado o Alceste, um software amplamente utilizado na análise de banco de dados textuais, que realiza a análise lexicográfica mostrando as unidades de contexto elementar (UCEs), caracterizadas pelas palavras e por segmentos de textos que compartilham essas palavras. O corpus inicial é dividido em classes que podem indicar os agrupamentos de conteúdos de determinados objetos e possibilitam a interpretação do conjunto textual (NASCIMENTO; MENANDRO, 2006).

No relatório fornecido pelo software, o corpus apresentou 8105 ocorrências de palavras, sendo 1851 palavras distintas. Foram formadas 196 UCEs, das quais 87,76\% (172 UCEs) foram consideradas na classificação hierárquica descendente (CHD). A Figura 1 a seguir apresenta a organização do corpus em quatro classes distintas e mostra as relações entre as classes (CAMARGO, 2005). Nessa figura, também pode ser visualizado o número de UCEs que compõem cada classe, bem como a porcentagem em relação ao número total de UCEs selecionadas. Observa-se que a nomeação das classes foi feita de acordo com as principais palavras que nelas se faziam presentes. O valor mínimo do X2 (qui quadrado) considerado é 3,84.

Figura 1 - Dendograma ilustrando os elementos característicos de cada classe

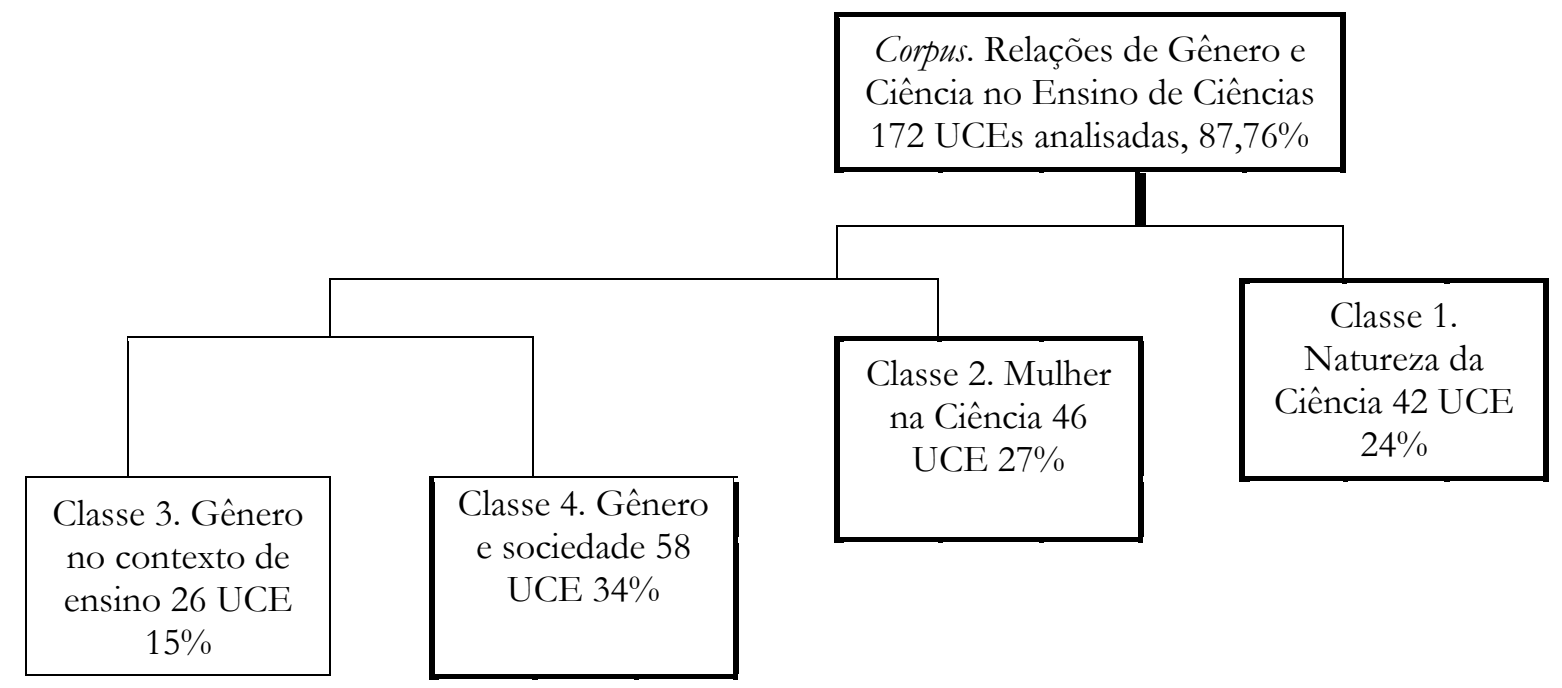

Fonte: Elaborada pelas autoras com base nos dados da pesquisa. 
A compreensão dimensional das RS compreende a integração dos conhecimentos, das imagens e das atitudes (MOSCOVICI, 2012). Os conhecimentos circulantes foram analisados a partir dos relatórios emitidos pelo Alceste e apontaram as classes (1, 2, 3 e 4). Há elementos que escapam à análise lexical e necessitam da análise de conteúdos, pois aparecem ao longo das informações como sinalizadores que extrapolam a linguagem convencional. São as atitudes e as imagens que serão explicitadas no texto.

Serão discutidas as classes obtidas a partir do tratamento de todos/as os/as investigados/as, seguindo o critério da análise do geral ao particular. A análise do corpus separou a classe 1 das demais; nessa classe, apresentam-se as discussões da Natureza da Ciência. As classes 3, 4 e 2 aproximam-se entre si, sendo representadas pelas discussões de gênero no contexto de ensino, na sociedade e na Ciência.

A classe 3 - Gênero no contexto de Ensino - advém das informações associadas a todas as variáveis censitárias analisadas. Os sujeitos da classe são: a gente (professor/a), homem/ns, mulheres, menino/as e filho, e as ações associadas e eles são as de virar, perceber, cair, escrever, interessar, obrigar, reforçar e concluir. Os objetos a que se referem são espaço, sala de aula, escola, curso, capacidade, diferença, característica, interesse, questão, reforço e visão. A presença dos adjetivos "social" e "iguais" é relativa às construções sociais de gênero, indicando a reinvindicação de igualdade de direitos entre homens e mulheres, mas respeitando suas diferenças, sem atentar que essas diferenças não podem ser a causa das discriminações.

O modelo de docência sensível a gênero destaca que, para "[...] promover a mulher em todos os espaços, é necessário um ensino inovador buscar nos campos da pesquisa o que lhe interessa, possibilitar a escolha" (B10 M). A atitude dessa docente é favorável ao objeto de representação, ao citar pesquisas que "[...] separam sala de meninas e sala de meninos [...] que se sobressaem melhor quando estão separados [...], será que de fato porque estão separados, ou é questão externa à sala de aula?”. Ela demostra informação a respeito do contexto social da construção de gênero e questiona a Ciência e a divulgação científica, pois "[...] as pesquisas podem ser tendenciosas [...], nós precisamos sim enquanto professores verificar a verdadeira função daquela entrevista, reportagem, publicação" (B10M).

Nessa classe, também surge uma informação referente à falta de inclusão de meninas nas áreas tecnológicas. A docente informa que "[...] vão fazer um trabalho para as meninas das escolas perto da UTFPR dando aula para elas, para elas verem que não é um bicho de sete cabeças, que elas também podem, para estimular e saber que aquilo também pode ser um futuro para elas" (B5 M). A imagem que essa docente apresenta é a de que as mulheres/meninas não possuem as mesmas oportunidades, e a atitude indicada é favorável à inclusão.

O docente de Matemática fala: "Não dar aulas igual para homens e mulheres, sério? Isso é inferência. No magistério, a maioria que a gente percebe são mulheres, (mas) no curso de engenharia são homens" (M19H). Essa fala demonstra a ambivalência da discriminação no ambiente escolar com a docência, independentemente de gênero. A segregação de mulheres e de homens em cursos distintos reforça o estereótipo social da mulher no âmbito privado, doméstico, a que o magistério remete (LOURO, 2003), e no espaço público os homens são representados pelos cursos científicos e tecnológicos. Pesquisas mostram-nos que a maneira como as/os docentes ensinam, tratam, respondem suas/seus alunas/os não é livre de gênero (BOURDIEU, 2014; SCANTLEBURY; BAKER, 2006), que na escola são reproduzidas diferenças sociais e impostos padrões culturais.

Há materiais didáticos, como uma gravura, que também apontam para a discriminação da mulher: "[...] ali do livro didático em que os homens aparecem na frente e a mulher atrás [...]. 
Tem professores que nunca vão perceber" (F11M). Outra docente comenta que isso "[...] não tem fundamentação [...], não é que você não queira [...] pode até buscar fora, mas qual a fonte?" (B3M). São informações que explicitam a falta de materiais didáticos que possam dar suporte para um ensino que leve em consideração as questões de gênero. A docente L15M traz a informação do reforço de estereótipos: "Isso do aluno precisar de mãe é construído. Quando nós mulheres assumimos todas as responsabilidades, nós também reforçamos os estereótipos” (L15M).

A negação da discriminação das mulheres no ambiente de ensino é justificada pelos homens. Segundo um docente, hoje, os homens constituem a minoria a terminar o Ensino Superior porque "[...] começam a trabalhar mais cedo e [...] fatalmente desiste(m) do ensino superior". As questões sociais precisam ser consideradas, existem diferentes tipos de homens. E o referido docente continua: "Elas concluem mais por quê? Porque são mais capazes que os homens? Daí a gente vai cair no mesmo extremo. Elas não vão para cursos técnicos e tecnológicos porque têm menos capacidade [...]" (F12H). A falta de estímulo a que as mulheres são submetidas em relação a certas carreiras, em especial às tecnológicas e cientificas, é que as mantém afastadas de todo contato com os aspectos do mundo real "[...] para os quais não foram feitas" (BOURDIEU, 2014, p. 91).

As informações da classe 3 levantam questionamentos sobre o material didático livre de gênero, as mesmas oportunidades no ensino para as meninas e a sensibilidade do ensino ao gênero. Existem atitudes favoráveis associadas a informações contraditórias, como a de que aulas inovadoras podem minimizar as problemáticas de gênero na escola, a inclusão e as atitudes desfavoráveis de naturalização, de invisibilidade e de não reconhecimento da problemática de gênero no contexto de ensino.

A classe 4, Gênero e Sociedade, que está associada à classe 3, foi e continua sendo a mais extensa (58 UCEs - 34\%) e também deriva das informações associadas a todas as variáveis de análise. Os sujeitos da classe são crianças, homens, mulheres, indígenas, caçadores e professor/es, e as ações associadas e eles são as de acontecer, chorar, conseguir, continuar, discriminar, dizer, faltar, fazer, ficar, ir, olhar, tentar e trazer. Os objetos a que se referem são bullying, caverna, cérebro, documentário, gênero, ideologia, imagem, livro, questão e relação. Os adjetivos "pré-histórica", "diferente", "forte" e "independente" estão relacionados à busca de argumentos em origens remotas em cavernas, caçadores e indígenas, ou em origens biológicas no cérebro. Essas falas estão relacionadas, por vezes, ao reconhecimento das questões de gênero, mas também à tentativa de naturalização, de discriminação, e ao não reconhecimento dessas questões.

Em sua fala, a docente F11 reconhece as relações desiguais de poder em que estão implicadas as mulheres desde "[...] lá na pré-história, o poder, o que era o poder, o físico, hoje, o financeiro". Essa informação remete à imagem de violência física e simbólica a que as mulheres são submetidas (BOURDIEU, 2014). A informação trazida pelo docente M19, em que cita um livro que relata uma pesquisa em que foram apresentadas crianças chorando, e "[...] as mulheres conseguiram definir tipo por que ela estava chorando, por fome, por isso ou por aquilo, [...] 80\% das mulheres conseguiram definir só olhando", reafirma a posição social determinada à mulher como cuidadora inata. A imagem de uma "intuição feminina" está relacionada à submissão "[...] que estimula, ou obriga, a atenção, e as atenções, a observação e a vigilância necessárias para prever desejos ou pressentir os desacordos" (BOURDIEU, 2014).

A informação do docente G14 é coerente com a posição de poder ocupada pela maioria dos homens nas companhias aéreas em que as mulheres "[...] só são comissárias de bordo, piloto só homens", e continua: "[...] se não caia muito avião, se fosse uma pilota mulher eu pulava do avião". Nesse "tom de brincadeira", o depoente exerce uma violência sutil, invisível, 
imperceptível, naturalizada, em relação às mulheres. Podemos inferir que essa representação de mulher incapaz para assumir determinadas posições pode influenciar a maneira como docentes agem e tratam homens e mulheres. Assim, tanto "[...] as representações individuais ou sociais fazem com que o mundo seja o que pensamos que ele é ou deve ser" (MOSCOVICI, 2012, p. $55)$.

Se na classe anterior o espaço das relações de gênero era o escolar, na classe 4 esse espaço é, predominantemente, o social, sustentado por uma argumentação ancestral e biológica. Mudamse o espaço e a argumentação, mas as divisões tidas como naturais são mantidas. A rejeição masculina do princípio da igualdade, como reinvindicação feminina, chega à naturalização da força e do poder, afirmando: "[...] ser forte é uma característica do ser humano para ter o poder, você tem que ser forte, independente(mente) de ser mulher" (G13M).

A classe 2, Mulher na Ciência, é protagonizada pelos sujeitos cientista, pesquisador, a gente e outro/s, associados a ações de chegar, desistir, dizer, entender, entrar, fazer, pegar, pensar, saber, ser e ver. Os objetos associados a eles são amuleto, curso, ensino, disciplina, discurso, escolha, exemplo, parte, processo, resultado e trabalho. Atravessa os sujeitos, suas ações e os objetos ligados a ela, o adjetivo que qualifica o campo discursivo como difícil. Trata-se da produção de conhecimento como um processo que não é fácil e está associada à imagem do cientista que abdica da vida social e pessoal, como se pode observar neste trecho:

\begin{abstract}
Veja bem, você já parou para pensar, por exemplo, que as mulheres entram nos cursos e desistem, já parou para pensar que pode ser um amuleto esse negócio de machismo, porque, veja bem, chega lá, vê que é pauleira, acha esse amuleto de desculpa. Segundo ponto, veja bem, é muito difícil para a mulher desistir de ir num salão de beleza, de ficar uma hora na frente do espelho, de desistir de ir à academia. Porque um cientista tem que ser dedicado porque justamente as disciplinas mais exatas são também as mais desistentes. Será que não tão utilizando isso como amuleto? Tem que parar para pensar também [...]. Eu acho que existe muito amuleto aí também na hora que tem que desistir de tudo até do namorado, aí cai fora. O pesquisador, você sabe, está pesquisando exclusivo, não tem mulher, não tem filho, não tem nada, tem que pesquisar. Se ela for pesquisadora, ela não pode ter marido, filhos, vida familiar, ela tem que abdicar disso, ela tem que abdicar. (G14H).
\end{abstract}

$\mathrm{Na}$ visão desse docente, as mulheres não devem fazer parte do contexto científico "[...] para o qual não foram feitas" (BOURDIEU, 2014, p. 91). A representação social da mulher é a de que ela não possui as características fundamentais de um cientista. A atitude desse docente não é favorável à inclusão da mulher no meio científico. As docentes de literatura e filosofia representam o cientista como indivíduo "dedicado, disciplinado" (L15M); por outra docente, ele é visto como "[...] um carinha maluquinho que o trabalbo dele é isolado e a gente sabe que não é isolado" (F11M). Essas imagens do cientista são coerentes com as concepções atuais de cientista e seu papel na construção da Ciência (GIL PÉREZ, 2001).

Em outro extremo da dificuldade na discriminação do campo, merece destaque a reação à reinvindicação da igualdade de oportunidades de gênero. Recorre-se ao princípio da aptidão masculina para a ciência com o argumento de que "[...] as mulheres entram nos cursos e desistem" porque o curso é "pauleira". As críticas feitas são comparadas a um sortilégio, "amuleto" ou desculpa por não serem capazes de enfrentar as dificuldades da ciência.

A Classe 1 - Natureza da Ciência - caracteriza-se como uma classe objetiva, sem anúncio de sujeito. Essa classe, por suas características, está separada das demais classes. Os substantivos estão relacionados à organização do conhecimento científico: teoria, modelo, hipótese, conhecimento, ordem, observação, experimento, inferência, termos e ideia. As ações 
destacadas são: observar, colocar, provar, conhecer, parecer e acreditar como ações realizadas pelos pesquisadores na construção do conhecimento científico.

Trata-se de um conjunto de declarações sobre os objetos e as ações da ciência de sujeitos anônimos. No discurso das/os docentes coexistem erros e acertos sobre a natureza da Ciência e de sua construção tanto no conjunto de informações quanto na fala de um/a mesmo/a docente, sinalizando a presença de conflito epistemológico. Os equívocos estão na crença da linearidade da construção do conhecimento científico: "[...] teoria vem depois de hipótese, de certas teorias foram criadas leis, modelos depois" (B8M); "[...] primeiro o modelo, depois teoria científica irrefutável, daí explica a hipótese mesmo, porque tem vários modelos de Ciência” (F11M); “[...] modelo é um esquema, vou fazer minhas inferências em cima desse trabalho, daí eu vou procurar uma teoria, daí eu vou procurar uma lei que um pesquisador bom tem que chegar a uma teoria" $(\mathrm{G} 13 \mathrm{H})$. Contudo, durante as discussões e pela falta de um consenso entre as/os docentes, eles passam a reelaborar suas informações, e a imagem não linear da construção do conhecimento científico passa a fazer parte do discurso:

[...] não existe relação que um termo científico venha na frente do outro nesse sentido que está sendo organizado no quadro, a gente discutiu no grupo, e chegamos à seguinte conclusão: isso depende muito de quem vai observar, não quem vai observar, do pesquisador, todas elas estão interligadas, mas sem uma relação, de primeiro uma observação depois uma hipótese, uma teoria. (M19H).

Por isso que a observação e a hipótese podem inverter a ordem. Se ele é estudante de uma teoria, ele já vem fazendo observações e inferências, inclusive a respeito das observações, por isso que o que o meu colega disse ali, da não linearidade, e nós concordamos nesse sentido, é muito difícil estabelecer uma ordem. (L15M).

Imagens equivocadas de Ciência e de sua construção, que atribuem a essência da atividade científica à experimentação, como na fala do docente: "O conhecimento científico é confiável porque passou por experimento" (G14H), coincidem com uma ideia de "descoberta" científica. Essa representação é amplamente assinalada na literatura e foi denominada por Gil Pérez (2001) como empírico-indutivista.

Existem aspectos da $\mathrm{NdC}$ que são corroborados entre diversos especialistas da área, dentre os quais podemos citar a Ciência como conhecimento provisório e empírico, com observações carregadas de teorias, a presença de elementos imaginativos e criativos, social e culturalmente incorporados, que envolvem valores, conhecimentos e experiências anteriores dos cientistas, entre outros (ABD-EL-KHALICK, 1998; OSBORNE et al., 2003). Imagens adequadas de Ciência e de sua construção foram citadas pelas/os docentes, como: "Achando a verdade como verdade absoluta, como você comentou, em relação à deriva continental, não existe essa verdade absoluta, quando a gente vai estudando, vai abrindo" (B3M). Essa docente representa a Ciência como um processo de permanente construção.

$\mathrm{Na}$ análise das classes a partir dos relatórios do software, não foram nomeadas as tensões entre as variáveis que identificam os informantes, mas que estão latentes quando se compara as falas de gênero. Para ampliar a discussão, promoveu-se a análise comparando os grupos de informantes. Para destacar as especificidades e as diferenças marcantes de cada grupo, levaram-se em consideração as áreas de formação e sexo. Em relação às áreas de formação, Ciências Naturais e Matemática foram analisadas em separado da área de Humanas, na qual, pelo uso do software Alceste, não foi possível encontrar uma diferença significativa de argumentação. Nesse sentido, podemos inferir que a área de formação não problematiza as questões de gênero e da Natureza da Ciência. Nesse particular, as/os docentes reproduzem as informações circulantes na sociedade. Assim, a formação inicial e continuada não está contribuindo independentemente da área para

Práxis Educativa, Ponta Grossa, v. 12, n. 3, p. 995-1012, set./dez. 2017 Disponível em: <http://www.revistas2.uepg.br/index.php/praxiseducativa > 
um ensino mais equânime em relação a gênero. As discussões quando ocorrem são isoladas e não integram os currículos formais das licenciaturas, sendo necessária a discussão na reestruturação dos currículos para empoderar as discussões de gênero nas universidades.

Em relação às mulheres e aos homens, existe diferença. No Quadro 2, é possível observar as palavras de ambos os grupos, obtidas pelo processamento parametrizado do Alceste.

Quadro 2 - Classificação hierárquica descendente do corpus textual, comparando as informações de homens e mulheres

\begin{tabular}{|c|c|c|c|c|c|}
\hline \multicolumn{3}{|c|}{$\begin{array}{c}\text { Homens com } 72 \text { UCE } \\
(36,7 \%)\end{array}$} & \multicolumn{3}{|c|}{$\begin{array}{c}\text { Mulheres com } 124 \text { UCE } \\
(63,3 \%)\end{array}$} \\
\hline Palavras & Freq. & $\mathrm{X}^{2}$ & Palavras & Freq. & $\mathrm{X}^{2}$ \\
\hline Conseguiram & 7 & 9,25 & Conhecimento & 13 & 5,68 \\
\hline Grupo & 5 & 8,84 & A gente & 31 & 4,38 \\
\hline Hora & 5 & 8,84 & Escolha & 7 & 4,22 \\
\hline Desistir & 6 & 7,49 & Tenho & 7 & 4,22 \\
\hline Veja & 6 & 7,49 & & & \\
\hline Mundo & 4 & 7,03 & & & \\
\hline Negro & 4 & 7,03 & & & \\
\hline Pergunta & 8 & 6,50 & & & \\
\hline Espaço & 5 & 5,78 & & & \\
\hline Tipo & 5 & 5,78 & & & \\
\hline Amuleto & 3 & 5,25 & & & \\
\hline Lado & 6 & 5,25 & & & \\
\hline Pequenas & 3 & 5,25 & & & \\
\hline Outro & 13 & 4,39 & & & \\
\hline Acredita & 4 & 4,13 & & & \\
\hline Indígena & 4 & 4,13 & & & \\
\hline Questionando & 4 & 4,13 & & & \\
\hline Seguinte & 4 & 4,13 & & & \\
\hline
\end{tabular}

Fonte: Elaborado pelas autoras com base nos dados da pesquisa.

$*$ Freq. $=$ Frequência.

As palavras do Quadro 2 mostram uma representação distinta das docentes e dos docentes. Os verbos mais utilizados pelos docentes foram conseguir, as mulheres conseguem porque é natural, e desistir, as mulheres desistem porque é difícil. $\mathrm{E}$ as docentes usaram mais os verbos conhecer, no sentindo de compreender as questões de gênero na Ciência, e escolher, que se refere à possiblidade de escolha da mulher e das/dos cientistas ao realizarem seu trabalho. 
Essa análise mostra uma RS dos homens naturalizada, discriminatória e de negação das questões de gênero na sociedade e na Ciência, mais contundente do que nas representações das mulheres. As representações naturalizadas de ser mulher e homem podem se exemplificar na fala do docente $\mathrm{M} 19 \mathrm{H}$ :

[...] confirmar esse lance do instinto da mulher perceber essas coisas. [...] (Está) no subconsciente já vem com a mulher da caverna e ela consegue fazer isso se a gente pensar na mulher na hora de estacionar. [...]. Outra pesquisa que me fez ficar questionando [...] é que ele perguntou para várias pessoas em que lado o homem dormia na cama [...], a maioria dos homens dorme do lado da porta [...], porque os homens da caverna dormiam do lado da porta para proteger as mulheres e crianças. (M19H).

O instinto feminino é apresentado como uma imagem de mulher idealizada, que reafirma a representação dos papéis sociais a que as mulheres são submetidas (sexismo benévolo). Nessa imagem, de mulher intuitiva, pode-se citar como exemplo o "instinto materno", que envolve dedicação, abnegação, generosidade, ternura, entre outros adjetivos. Espera-se que a mulher tenha naturalmente esse instinto e, quando não o tem, é socialmente discriminada. A imagem do homem como protetor da mulher e da criança também é uma imagem idealizada e ambivalente, uma vez que também é aceita a imagem do homem como dominador por sua maior autoridade, poder e força física. É uma forma de sexismo sutil, aparentemente positiva, com base na dominação masculina (GLICK; FISKE, 1996 apud FORMIGA; GOUVEIA; SANTOS, 2002; MLADINIC et al., 1998 apud FORMIGA; GOUVEIA; SANTOS, 2002).

O fragmento textual do docente $\mathrm{M} 19 \mathrm{H}$ apresenta uma imagem ingênua da construção do conhecimento científico, utiliza a citação de um manual de autoajuda para afirmar comportamentos de homens e de mulheres em uma perspectiva sexista. Deve-se duvidar de tudo que é tomado como natural e fixo para cada gênero (LOURO, 2003). Essa representação pode orientar a atitude desse docente, uma atitude marcada pela segregação naturalizada de papéis.

A representação discriminatória pode ser observada no trecho: "Veja bem, você já parou para pensar, por exemplo, que as mulheres entram nos cursos e desistem, já parou para pensar que pode ser um amuleto esse negócio de machismo porque, veja bem, chega lá, vê que é pauleira, acha esse amuleto de desculpa" (G14H). O docente julga que o trabalho do cientista é difícil e que, por isso, as mulheres desistem de tal encargo. Não considera, por exemplo, os problemas sociais impostos às mulheres. No artigo de Silva e Ribeiro (2014), aborda-se a trajetória acadêmica e profissional de mulheres na Ciência por meio de entrevistas realizadas com mulheres cientistas em universidades públicas. O artigo revela situações explícitas e implícitas de preconceitos de gênero e evidencia a problemática de conciliar sua profissão com as responsabilidades familiares.

A representação de negação das questões de gênero pode ser observada no discurso do docente M19H: "Porque ela entra (universidade), tem uma resistência, aí sim, porque seria um espaço mais de homens, mas hoje ela desiste por que dali? Na hora que ela está lá dentro é igual porque os professores dão aulas para homens e mulheres". A educação estimula desigualdades e favorece mais os meninos, que são objeto de um tratamento privilegiado (BOURDIEU, 2014). Desse modo, essa representação pode gerar atitudes que reproduzem as desigualdades e corroboram com a discriminação.

$\mathrm{O}$ docente $\mathrm{F} 12 \mathrm{H}$ cita algumas pesquisadoras como meio de provar que as mulheres não são discriminadas no meio acadêmico e científico:

[...] mas também tem outro lado que deve ser enfocado. Mas, por exemplo, na USP, que é uma universidade bastante conservadora, em filosofia os pesquisadores de ponta

Práxis Educativa, Ponta Grossa, v. 12, n. 3, p. 995-1012, set./dez. 2017 Disponível em: < http://www.revistas2.uepg.br/index.php/praxiseducativa > 
hoje são mulheres, Salma; Scarlet; a própria Marilene Chauí, que eu não gosto muito, mas tem gente que gosta; a própria Aranha, que escreveu o livro didático. Olha, são no mínimo cinco mulheres numa universidade tradicional. $(\mathrm{F} 12 \mathrm{H})$.

A Ciência sempre foi vista como uma atividade praticada por homens, e os estudos históricos em relação à participação feminina no mundo científico têm mostrado uma quase ausência de registros de produção científica feminina. No entanto, as mulheres estavam presentes no meio científico, porém invisibilizadas, muitas vezes dando suporte ao pesquisador (LETA, 2003). Pesquisadoras como Evelyn Fox Keller, Sandra Harding, Donna Haraway, Helen Longino e Londa Schiebinger, entre outras, problematizaram a ausência das mulheres na Ciência, as consequências da sua sub-representação histórica e as contribuições do movimento feminista para essas discussões.

$\mathrm{Na}$ presente pesquisa, as representações sociais das mulheres mostram sensibilidade em relação a gênero na Ciência, na sociedade e na escola. Entretanto, concordamos com Uma Narayan (1989 apud ARRUDA, 2000, p. 123), ao citar que "[...] ser oprimido não é garantia de que se pensa como tal, assim como não sê-lo não implica obrigatoriamente ser insensível".

A pesquisa de Montecinos e Anguita (2015) traz resultados semelhantes aos desta investigação. As autoras realizaram entrevistas com seis futuras/os docentes chilenas/os de Física e analisaram seus discursos. Os resultados mostram que mulheres estão mais cientes das questões de gênero na educação, embora não possuam conhecimento teórico. A docente $\mathrm{B} 3 \mathrm{M}$ reconhece essa problemática: "Agora a gente já começa a buscar mais leituras para entender melhor depois do curso de formação”. E a docente B10M afirma:

Os saberes necessários aos docentes primeiro são informações mais atualizadas, os novos conhecimentos para perceber que, [...], a gente tem conceitos formados errados, porque [...] tem que saber que existem outros conceitos diferentes do que a gente tem; então, primeiro, é a informação, estudo e pesquisa. (B10M).

Em outras descrições, as docentes percebem as questões de gênero na Ciência e questionam: "Mas será que os homens tinham essa noção de que eles tinham que ser provedores, será que não era cada um por si? Para mim, saber que eu sou provedora da minha casa eu tinha que ter consciência, tenho que saber, vai que cada um é por si” (F11M).

Hoje, há duas hipóteses explicativas para a evolução humana. A primeira é centrada no Manhunter, o homem caçador e seu papel crucial na evolução dos seres humanos para a forma hoje conhecida. A interpretação dos dados foi elaborada por meio da observação de pedras lascadas, que foram então tomadas como evidência inequívoca de caça. Assim, foi inferido que os machos são centrais não apenas para a evolução da espécie, mas para a sobrevivência dos membros de um grupo.

Esse cenário foi consistente com o homem branco, cultura que dominava círculos científicos até os anos de 1960 e início dos anos de 1970. A segunda hipótese foi desenvolvida quando o movimento feminista ficou mais forte, as mulheres reivindicaram o reconhecimento nas várias disciplinas científicas, e a história da evolução dos hominídeos começou a mudar. Uma história que é mais consistente com uma abordagem feminista é centrada na mulher coletora e seu papel central na evolução dos seres humanos (LONGINO; DOELL, 1983; LEDERMAN; ABD-EL-KHALIC, 1998).

Essas duas explicações permitem perceber a natureza epistemológica arbitrária da Ciência. As duas hipóteses são alvos de críticas, uma vez que mantêm os dualismos. Nesse sentido, a docente L15M apresenta uma representação social de Ciência não neutra: "Não existe um discurso que venha isento de outros discursos que seja puro, tudo parte de um pressuposto. São 
esses pressupostos que fazem, seja para confirmar ou para negar. Quando a gente escolhe uma metodologia, na verdade nós estamos escolhendo também uma ideologia, um discurso". E complementa: "[...] é muito mais interessante o processo da escolha, o cientista tem esse trabalho, também um trabalho bem árduo e interessante é o de Rubem Alves, porque, como ele é da literatura, ele sabe que o trabalho poético literário talvez seja um dos trabalhos mais difíceis [...]”.

A docente $\mathrm{B} 8 \mathrm{M}$ reconhece o desconhecimento das questões de gênero na construção do conhecimento científico, quando menciona: "Até eu levei um susto, até eu, porque a gente ensinava que esse hormônio testosterona era mais, era masculino. Agora que eu entrei na menopausa, o médico falou que devo fazer reposição hormonal". Na história da Ciência, mostrase a distinção entre hormônios masculinos e hormônios femininos, o que favorece a ideia de que a testosterona só existe no corpo masculino e o estrogênio no corpo feminino, fato que não é real (FAUSTO-STERLING, 2000) e reforça uma representação dualista de sexo.

No Ensino de Ciências, a representação de dualidade é reforçada em materiais didáticos. Na pesquisa realizada por Nehm e Young (2008), mostra-se que, em livros didáticos dos Estados Unidos, ainda se discute os hormônios sexuais como sendo distintos para homens e mulheres. No trabalho realizado por Silva e Coutinho (2016), os autores analisaram livros didáticos de Biologia aprovados pelo Programa Nacional do Livro Didático de 2011. Os pesquisadores levantaram as categorias "noção binária de gênero/sexo", "heteronormatividade", "definição da fêmea pela ausência", "normatização dos comportamentos" e "biologia como destino" para analisar os textos de hormônios. Pelas análises, os autores concluíram que esses materiais produzem uma ignorância em Biologia que possibilita o sexismo e a discriminação de gênero.

\section{Considerações finais}

O corpus analisado expõe três campos discursivos: a natureza da ciência, a mulher na ciência e o gênero no contexto de ensino e na sociedade. Esses campos apresentam-se atravessados por tensões de gênero, constantemente naturalizados e também questionados a partir da natureza da Ciência, indicando a primazia argumentativa das representações sociais na análise do lugar da mulher na ciência e do gênero no contexto de ensino e na sociedade.

Nas áreas de formação - Ciências Naturais e Matemática e Humanas - pelo uso do software Alceste, não foi possível encontrar uma diferença significativa de argumentação em relação às questões de gênero na sociedade, na Ciência e no Ensino de Ciências. Esse dado pode ser um indício de que todas as áreas ainda são carentes de reflexões, no processo de formação inicial e continuada, fato que abre caminhos para novas investigações.

Foi possível, por meio dos dados empíricos, perceber a argumentação distinta de homens e mulheres. A RS dos homens, que é naturalizada, discriminatória e de negação das questões de gênero na sociedade e na Ciência, é mais contundente do que as representações das mulheres. Essa RS desumaniza tanto homens quanto mulheres, estas de forma mais violenta. Como aprofundamento das pesquisas propõe-se: As RS das/dos docentes interferem na interação social escolar? De que maneira?

O texto apresentado defende: o processo formativo baseado na concorrência equitativa, na desconstrução das dicotomias e na problematização da natureza do gênero, sob o princípio de que um gênero contém o outro e de que ambos são plurais; a ideia da Ciência como um saber situado, pois o conhecimento científico é construído em um determinado contexto social e cultural, no qual homens e mulheres são sujeitos históricos e socialmente situados; o fato de que 
na Educação Científica a filosofia feminista situada é uma possibilidade de igualdade de acesso e condições aos campos científicos e sociais.

Do processo formativo vem a demanda, expressa no desejo de ter mais acesso a conhecimentos que esclareçam melhor as controvérsias e as ambiguidades enfrentadas cotidianamente. A natureza da ciência, ao coordenar os campos argumentativos da mulher no seu interior e as questões de gênero, sugere que a epistemologia crítica pode ser um dos focos prioritários para a análise desses problemas.

\section{Agradecimentos}

Agradecemos ao Prof. Dr. Ademir José Rosso (UEPG) por processar o corpus textual no software Alceste e pelos comentários ao manuscrito.

Agradecemos também a Capes e ao CNPq.

\section{Referências}

ABD-EL-KHALICK, F. The influence of history of science courses on students conceptions of the nature of science. 1998. 547 f. Tese (Doutorado em Filosofia) - Oregon State University, Oregon, Corvallis, 1998.

ABD-EL-KHALICK, F.; LEDERMAN, N. G. Improving science teachers' conceptions of nature of science: A critical review of the literature. International Journal of Science Education, v. 22, n. 7, p. 665-701, jul. 2000. DOI: 10.1080/09500690050044044

AKERSON, V. L. et al. Developing a community of practice to support preservice elementary teachers' nature of science instruction. International Journal of Science Education, v. 34, n. 9, p. 1371-1392, jun. 2012. DOI: 10.1080/09500693.2011.639100

ALVES-MAZZOTTTI, A. J. Representações sociais: aspectos teóricos e aplicações à educação. Múltiplas Leituras, São Paulo, v. 1, n. 1, p. 18-43, jan./jun. 2008. DOI: 10.15603/19828993/ml.v1n1p18-43

ANDERSON, E. Feminist Epistemology and Philosophy of Science. In: ZALTA, E. N. (Ed.). The Stanford Encyclopedia of Philosophy (Spring 2011 edition). 2011. Disponível em: $<$ http://plato.stanford.edu/archives/spr2011/entries/feminism-epistemology/>. Acesso em: 6 mar. 2014.

ARRUDA, A. Teoria das representações sociais e teorias de gênero. Cadernos de Pesquisa, São Paulo, n. 117, p. 127-147, nov. 2002. DOI: 10.1590/s0100-15742002000300007

ARRUDA, A. Feminismo, gênero e representações sociais. Textos de História, Brasília, v. 8, n. 1-2, p. 113-137, 2000.

BARDIN, L. Análise de conteúdo. 3. ed. Lisboa: Ed. 70, 2004.

BOURDIEU, P. A dominação masculina. 2. ed. Rio de Janeiro: BestBolso, 2014. 
CAMARGO, B. V. ALCESTE: um programa informático de análise quantitativa de dados textuais. In: MOREIRA, A. S. P. et al. (Org.). Perspectivas teórico-metodológicas em Representações Sociais. João Pessoa: Ed. Universitária da UFPB, 2005. p. 513-539.

FAUSTO-STERLING, A. Sexing the body: gender politics and the construction of sexuality. New York: Basic Books, 2000. Disponível em: <https://libcom.org/files/Fausto-Sterling\%20\%20Sexing\%20the\%20Body.pdf>. Acesso em: 12 nov. 2013.

FORMIGA, N. S.; GOUVEIA, V. V.; SANTOS, M. N. Inventário de sexismo ambivalente: sua adaptação e relação com o gênero. Psicologia em Estudo, Maringá, v. 7, n. 1, p. 103-111, jan./jun. 2002. DOI: 10.1590/s1413-73722002000100013

FRANCO, M. L. P. B. Representações sociais, ideologia e desenvolvimento da consciência. Cadernos de Pesquisa, São Paulo, v. 34, n. 121, p.169-186, jan./abr. 2004. DOI: 10.1590/s0100-15742004000100008

GIL PÉREZ, D. et al. Para uma imagem não deformada do trabalho científico. Ciência e Educação, Bauru, v. 7, n. 2, p. 125-153, 2001. DOI: 10.1590/s1516-73132001000200001

HARAWAY, D. Saberes localizados: a questão da ciência para o feminismo e o privilégio da perspectiva parcial. Cadernos Pagu, Campinas, n. 5, p. 7-41, 1995.

HARAWAY, D. The promise of monsters: a regenerative politics for inappropriate/d others. In: GROSSBERG, L.; NELSON, C.; TREICHLER, P. (Eds.). Cultural Studies. Londres: Routledge, 1992. p. 295-337.

HARDING, S. Ciencia y Feminismo. Madrid: Ediciones Morata, 1996.

HARDING, S. Gender, democracy, and philosophy of science. The Pantaneto Forum. n. 38. 2010. Disponível em: <http://www.pantaneto.co.uk/issue38/harding.htm>. Acesso em: 10 nov. 2013.

HEERDT, B. Saberes docentes: gênero, natureza da ciência e educação científica. 2014. 239 f. Tese (Doutorado em Ensino de Ciências e Educação Matemática) - Universidade Estadual de Londrina, Londrina, 2014.

HEERDT, B.; BATISTA, I. de L. Questões de gênero e da natureza da ciência na formação docente. Investigações em Ensino de Ciências, Porto Alegre, v. 21, n. 2, p. 30-51, ago. 2016a. DOI: 10.22600/1518-8795.ienci2016v21n2p30

HEERDT, B.; BATISTA, I. de L. Unidade didática na formação docente: natureza da ciência e a visibilidade de gênero na ciência. Experiências em Ensino de Ciências, Cuiabá, v. 11, n. 2, p. 39-60, 2016b.

HUSSÉNIUS, A. Science education for all, some or just a few? Feminist and gender perspectives on science education: a Special issue. Cultural Studies of Science Education, v. 9, n. 2, p. 255262, jan. 2014.

JODELET, D. Representações sociais: um domínio em expansão. In: JODELET, D. (Org.). As representações sociais. Rio de Janeiro: UERJ, 2001. p. 17-44. 
JODELET, D. Imbricações entre representações sociais e intervenção. In: MOREIRA, A. S. P.; CAMARGO, B. V. (Orgs.). Contribuições para a teoria e o método de estudo das representações sociais. João Pessoa: UFPB, 2007. p. 45-74.

KELLER, E. F. Qual foi o impacto do feminismo na ciência? Tradução de Maria Luiza Lara. Cadernos Pagu, Campinas, n. 27, p. 13-34, 2006.

LEDERMAN, N. G.; ABD-EL-KHALICK, F. Avoiding de-natured science: activities that promote understandings of the nature of science. In: MCCOMAS, E. F. (Ed). The nature of science in science education: rationales and strategies. Dordrecht: Kluwer Academic Publishers, 1998. p. 83-126.

LETA, J. As mulheres na ciência brasileira: crescimento, contrastes e um perfil de sucesso. Estudos Avançados, São Paulo, v. 17, n. 49, p. 271-284, set./dez. 2003. DOI: 10.1590/s010340142003000300016

LONGINO, H. Can there be a feminist science? Hypatia. v. 2, n. 3, p. 51-64, set. 1987. DOI: 10.1111/j.1527-2001.1987.tb01341.x

LONGINO, H.; DOELL, R. Body, bias, and behavior: a comparative analysis of reasoning in two areas of Biological Science. Signs: Journal of Women in Culture and Society, v. 9, n. 2, p. 206-227, dez. 1983. DOI: 10.1086/494044

LOURO, G. L. Gênero, sexualidade e educação: Uma perspectiva pós-estruturalista. Petrópolis, RJ: Vozes, 2003.

LOURO, G. L. Gênero e sexualidade: pedagogias contemporâneas. Pro-Posições, Campinas, v. 19, n. 2, p. 17-23, maio/ago. 2008. DOI: 10.1590/s0103-73072008000200003

MONTECINOS, A.; ANGUITA, E. Being a woman in the world of physics education: female physics student teachers' beliefs about gender issues, in the city of Valparaiso, Chile, from a qualitative perspective. Procedia - Social and Behavioral Sciences, v. 197, p. 977-982, jul. 2015. DOI: $10.1016 /$ j.sbspro.2015.07.286

MOSCOVICI, S. A psicanálise, sua imagem e seu público. Petrópolis: Vozes, 2012.

NASCIMENTO, A. R. A.; MENANDRO, P. R. M. Análise lexical e análise de conteúdo: uma proposta de utilização conjugada. Estudos e pesquisas em Psicologia, Rio de Janeiro, v. 6, n. 2, p. 72-88, jul./dez. 2006.

NEHM, R. H.; YOUNG, R. "Sex Hormones" in secondary school biology textbooks. Science \& Education. v. 17, n. 10, p. 1175-1190, abr. 2008. DOI: 10.1007/s11191-008-9137-7

OSADA, N. M.; COSTA, M. C. A construção social de gênero na Biologia: preconceitos e obstáculos na biologia molecular. Cadernos Pagu, Campinas, n. 27, p. 279-299, jul./dez. 2006. DOI: $10.1590 /$ s0104-83332006000200011

OSBORNE, J. et al. What "ideas-about-science" should be taught in school science? A Delphi study of the expert community. Journal of Research in Science Teaching. v. 40, n. 7, p. 692720, 2003. DOI: $10.1002 /$ tea.10105 
PINNICK, C. L. Science education for women: situated cognition, feminist standpoint theory, and the status of women in science. Science \& Education. v. 17, n. 10, p. 1055-1063, jul. 2008. DOI: $10.1007 / \mathrm{s} 11191-008-9153-7$

SALVI, R. F.; BATISTA, I. L. A análise dos valores na Educação Científica: contribuições para uma aproximação da filosofia da ciência com pressupostos da aprendizagem significativa. Experiências em Ensino de Ciências, Cuiabá, v. 3, n. 1, p. 43-52, 2008.

SCANTLEBURY, K.; BAKER, D. Gender issues in Science Education Research: remembering where the difference lies. In: ABEL, S. K.; LEDERMAN, N. G. Handbook of Research on Science Education. Londres: Routledge, 2006. p. 257-285.

SCHIEBINGER, L. O feminismo mudou a ciência? Bauru: Edusc, 2001.

SCOTT, J. Gênero: uma categoria útil de análise histórica. Educação \& Realidade, Porto Alegre, v. 20, n. 2, p. 71-99, jul./dez. 1995.

SILVA, F. A. R.; COUTINHO, F. A. Realidades colaterais e a produção da ignorância em livros didáticos de Biologia: um estudo sobre os hormônios e a questão de gênero. Investigações em Ensino de Ciências, Porto Alegre, v. 21, n. 3, p. 176-194, 2016. DOI: 10.22600/15188795.ienci2016v21n3p176

SILVA, F. F.; RIBEIRO, P. R. C. Trajetórias de mulheres na ciência: "ser cientista" e "ser mulher”. Ciência \& Educação, Bauru, v. 20, n. 2, p. 449-466, 2014. DOI: 10.1590/151673132014000200012

SILVA, A. F.; SANTOS, A. P. O.; HEERDT, B. Questões de gênero na educação científica: tendências nas pesquisas nacionais e internacionais. In: ENCONTRO NACIONAL DE PESQUISA EM EDUCAÇÃO EM CIÊNCIAS - ENPEC, 11., 2017, Florianópolis. Anais eletrônicos...Florianópolis: USFC, $2017 . \quad$ Disponível em: <http://www.abrapecnet.org.br/enpec/xi-enpec/anais/resumos/R2223-1.pdf>. Acesso em: 22 set. 2017.

SINNES, A. T.; LOKEN, M. Gendered education in a gendered world: looking beyond cosmetic solutions to the gender gap in science. Cultural Studies of Science Education, v. 9, n. 2, p. 343-364, jul. 2014. DOI: $10.1007 /$ s11422-012-9433-z

ZABALA, A. A prática educativa. Tradução Ernani F. F. Rosa. Porto Alegre: ArtMed, 1998.

Recebido em 30/07/2017

Versão corrigida recebida em 24/09/2017

Aceito em 27/09/2017

Publicado online em 03/10/2017

Práxis Educativa, Ponta Grossa, v. 12, n. 3, p. 995-1012, set./dez. 2017 Disponível em: < http://www.revistas2.uepg.br/index.php/praxiseducativa > 